\title{
The Freegan Challenge to Veganism
}

\author{
Josh Milburn $^{1}$ (D) Bob Fischer ${ }^{2}$
}

Accepted: 26 May 2021 / Published online: 5 June 2021

(c) The Author(s) 2021

\begin{abstract}
There is a surprising consensus among vegan philosophers that freeganism-eating animal-based foods going to waste-is permissible. Some ethicists even argue that vegans should be freegans. In this paper, we offer a novel challenge to freeganism drawing upon Donaldson and Kymlicka's 'zoopolitical' approach, which supports 'restricted freeganism'. On this position, it's prima facie wrong to eat the corpses of domesticated animals, as they are members of a mixed human-animal community, ruling out many freegan practices. This exploration reveals how the 'political turn' in animal ethics can offer fertile lenses through which to consider ethical puzzles about eating animals.
\end{abstract}

Keywords Veganism · Vegetarianism · Freeganism · Zoopolis · Animal ethics · Food ethics

Veganism is immoral. At least, that's the conclusion that Donald Bruckner (2015) defends. His argument begins with a standard case against eating products derived from intensive animal agriculture, which he calls the 'Factory Harm Argument':

(P1) Factory farming causes extensive harm to animals.

(P2) This harm is unnecessary.

(C1) The practice of factory farming causes extensive, unnecessary harm to animals.

(P3) It is wrong (knowingly) to cause, or support practices that cause, extensive, unnecessary harm to animals.

Josh Milburn

jmilburn02@qub.ac.uk

https://josh-milburn.com

Bob Fischer

fischer@txstate.edu

https://www.bobfischer.net/

1 Department of Politics and International Relations, The University of Sheffield, Sheffield, UK

2 Department of Philosophy, Texas State University, San Marcos, TX, USA 
(P4) Purchasing and consuming meat originating on factory farms supports the practice of factory farming.

(C2) Purchasing and consuming meat from factory farms is wrong. (Adapted from Bruckner, 2015, pp. 31-2).

So far, so familiar. Bruckner points out, however, that this argument doesn't entail a duty to be vegan (or, as Bruckner calls it, 'strict vegetarianism'). Why? 'The premises of the Factory Harm Argument, I [Bruckner] claim, support eating roadkill at least as much as they support eating vegetables' (2015, p. 33). The 'at least' is worth emphasising. As pointed out by some critics of veganism, including Steven Davis (2003) and Mike Archer (2011), arable agriculture involves harm to animals, who are killed in harvesting, have their homes destroyed, are poisoned by farmers, and so on. While the numbers may be disputed (Fischer \& Lamey, 2018), this doesn't matter for Bruckner's argument: 'Once we see that roadkill is a harm-free source of food and that vegetables are not harm free, we see that the reasons usually given for strict vegetarianism support an obligation not to be strict vegetarians but to eat some roadkill' (2015, p. 36). So, now it looks as though eating roadkill isn't simply permissible based on the premises of one of the better arguments for veganism: it's morally mandatory. ${ }^{1}$

A point that Bruckner doesn't make-but one noted by others (e.g., Fischer, 2018) - is that this argument seems to generalise to all non-vegan 'freegan' practices, such as 'dumpster-diving' for a can of beef stew, or finishing off ham sandwiches about to be thrown away after a departmental meeting. If Bruckner is right, then it's also wrong to eat a strict vegan diet when you could collect and consume any animal product that would otherwise be wasted, whether it would rot on a road verge or wind up in a landfill. ${ }^{2}$ Let's call this Bruckner-inspired way of eating the 'freegan diet', which involves eating vegan with the exception of any animal products that would go unused. ${ }^{3}$ We can contrast this with the 'strict vegan diet', which

\footnotetext{
1 Strictly speaking, this is not Bruckner's argument. He is only arguing for a conditional: namely, that if we accept the 'Don't cause or support extensive and unnecessary harm' principle, then we ought to eat roadkill. He himself rejects the 'Don't cause or support extensive and unnecessary harm' principle, but for simplicity's sake, we will talk as though he's arguing for roadkill consumption per se, since most people in the animal ethics literature are inclined to accept what he denies.

${ }^{2}$ We acknowledge that it may be wrong to describe these foodstuffs as wasted, because they may go on to be eaten by animals. Might the potential need of these animals work as an argument against picking up roadkill or dumpster diving? We think not. The argument would seem to generalize to any instance of humans gathering food that would otherwise be eaten by animals, which would presumably be most crops, most forage, and even most foods found in shops - given that they would be thrown out were they not sold. But perhaps the argument could serve to rebalance harms, a little. Even dumpster-diving or collecting roadkill is not harm-free, insofar as it removes opportunities that may be valuable for animals.

3 We acknowledge that our definition of the 'freegan diet' may not match precisely how the term freegan is used elsewhere, but it does usefully capture the issue we are here exploring. There is scholarly disagreement about how exactly to categorise and conceptualise freeganism, but a representative definition of the movement is Leda Cooks's: Freegans are individuals 'dedicated to participating as little as possible in a capitalist economy, choosing instead to forage and salvage unused or wasted consumer goods as a means of sustenance' (Cooks, 2017, p. 195). A crucial moment in the movement's history was the publication of a manifesto zine, Why Freegan?, that defines freeganism as 'essentially an anti-consumeristic ethic about eating' (Oakes 2000). Interestingly, the zine does explicitly criticise veganism, but not using
} 
does not involve the consumption of animal products at all, short of emergencies, because of a concern for harm to animals. ${ }^{4}$ Is it true that strict vegans ought to give up their veganism, becoming freegans instead? ${ }^{5}$

Let's note that even if we don't go that far, many philosophers seem comfortable with the conclusion that freeganism is morally permissible. Ted Warfield (2016), in a paper calling attention to the way that the wrongs of farming don't straightforwardly lead to the conclusion that meat-eating is immoral, observes that ' $[\mathrm{m}]$ ost writings on this topic remember to include a footnote indicating that [the authors] do not oppose the practice of eating factory farm products found in dumpsters and do not object to eating meat just about to be thrown into the garbage' (2016, p. 153).

We think that Warfield is right to point to this surprisingly common-and surprisingly underexplored ${ }^{6}$ - acknowledgement of the legitimacy of (some kinds of) meat eating in otherwise pro-vegan arguments. Bruckner (2015, p. 37) notes that David DeGrazia (2009, fn. 14) is open to eating dead animals found in woodlands; that Stuart Rachels (2011, p. 883) has little objection to eating meat about to be thrown away; and that Jordan Curnutt (1997, p. 156) is open to eating animals killed by accident. We can add a number of others to this list. Valéry Giroux (2016) notes that, even combined with environmental and health reasons, animal-focussed arguments for veganism don't preclude the restricted consumption of the bodies of certain animals who have died a natural death. Cheryl Abbate (2019b) describes freeganism as 'the least harmful way to eat', and, despite defending veganism (see also Abbate, 2019a), concedes that there is nothing categorically wrong with consuming animal flesh. Alasdair Cochrane (2012, p. 87) proposes a kind of institutionalised freeganism, in which animals are farmed for their corpses: they live a long and happy life, but they are butchered and eaten once they have died from natural causes. And Andrew Chignell (2016) suggests,

\section{Footnote 3 (continued)}

these Bruckner-esque arguments. Instead, it criticises veganism (which is nonetheless a 'good first step') because animals should not be our only concern:

I couldn't get behind any aspect of the corporate death consumer machine so I decided to boycott everything. ... Besides the concern that veganism as an ethic for eating stops short, it is also still a very high impact lifestyle. The packaging from vegan food doesn't take up less space in the landfill or consume less resources just because the food is vegan. The whole produce and consume dynamic is still played out, but the setting is a fancy health food store instead of a supermarket. Veganism is not a threat, or a challenge to the wasteful practices of our capitalist society. (Oakes 2000).

We accept, then, that freegans understood in this more expansive sense will have more criticisms of vegans than we explore here. We are interested, instead, in an internal critique of veganism that may be offered from a freegan perspective.

${ }^{4}$ People follow plant-based or vegan diets for a variety of reasons, but we are here interested, following Bruckner, in harm to animals.

${ }^{5}$ One of us (Fischer 2020) argues elsewhere that if this were true, it would be evidence against the premises that seemed to support veganism in the first place. If that's right, then the stakes in this debate may be higher than people have realized.

${ }^{6}$ Few animal ethicists have written about freeganism at any length, though there has been exploration in allied disciplines. The critical animal studies scholar Lauren Corman (2011) has explored the relationships between perceptions of freegans and perceptions of raccoons, for example - and critical animal studies scholars have a natural sympathy with both. 
though does not explore, that 'roadkill-itarians' and freegans may make the economic situation seeing animals harmed for food 'better, since they at least prevent the products of the system from going to waste' (2016, p. 184, emphasis Chignell's).

What's more, Peter Singer seems to approve of freeganism. Writing with Jim Mason, he describes freegans as 'impeccably consequentialist', adding that if 'you oppose the abuse of animals, but enjoy eating meat, cheese, or eggs - get it from a dumpster' (2016, pp. 222-3). Singer and Mason do not make the jump to saying that freeganism should be preferred to strict veganism. They come close, though: freeganism can be motivated, they say, by vegans realising that their approach is not radical enough, as '[e]ven products that contain no animal ingredients can hurt animals' (2016, p. 222). And they hold that agriculture's negative impact on animals 'could be reduced if we ate what would otherwise be wasted' (2016, p. 223). This is not the only time Singer broaches the subject; decades earlier, he apparently conceded (1980, pp. 327-8), in response to Cora Diamond, that he would 'be perfectly happy to eat the unfortunate lamb that has just been hit by a car' (Diamond, 1978, pp. 471-2).

It's plausible, then, that many of the most compelling arguments for veganism permit freeganism. This is admitted, more or less begrudgingly, by many of their proponents. What's more, freegans seem to have a good case against strict vegans - that is, freegans seem to have a good case that strict vegans ought to join them, or, at least, shouldn't condemn them.

This is our starting point. What can the strict vegan say by way of reply? In this paper, we explore several such responses. We begin with some standard moves that, ultimately, don't seem terribly promising. However, we spend most of the paper exploring the possibility that we can appropriately adopt a relationship with animals such that the eating of their corpses becomes impermissible. This is arguably what many vegans and vegetarians do. What's more, however, we may have an obligation to adopt such a relationship with certain animals-namely, domesticated animals-meaning that the consumption of their bodies is always prima facie impermissible. To motivate this claim, we turn to political theory, and, in particular, the zoopolitics of Sue Donaldson and Will Kymlicka (2011). Our conclusion, to anticipate, is that if we are willing to take seriously the idea that some animals are members of our political community, then we can marshal an interesting argument against some, though not all, freegan practices. It turns out that there are important distinctions to be drawn based upon the nature and origin of the scavenged foodstuff. For instance, found meat and found cheese may not belong in the same category, and some roadkill may not be equivalent to the body of an animal found deep in the backcountry. This is important, as it means that opponents of freeganism must be careful not to jump to conclusions to which they are not entitled. It could be that some critics of freeganism are opposed to particular instances of freeganism, not to freeganism per se. Based on our development of Donaldson and Kymlicka's zoopolitics, we ultimately describe what we will call a 'restricted freegan' position, in which the consumption of some scavenged animal products is permissible, but the consumption of others is prima facie wrong. 
Before we begin, it is worth situating the present enquiry. Political-philosophical approaches have been traditionally overlooked in conversations about human-animal relationships. As Kymlicka and Donaldson explain,

Political philosophy has been largely silent on the animal question, viewing it as an issue for ethicists but irrelevant to the core topics of political philosophy, such as theories of political community, democracy, boundaries, citizenship, the public good, civil society, sovereignty, and constitutionalism. Virtually all of the work done in contemporary political philosophy continues to assume that we can theorize these issues without taking animals into account. And, to be fair, this indifference is largely reciprocated. The vast bulk of the work done in animal ethics, whether based on animal welfare or animal rights, has not considered it necessary or helpful to connect animal ethics to the core concepts of political philosophy. (2016, p. 692)

Thankfully, this deficit began to be remedied in the 2010s, with a range of highquality works at the intersection of animal ethics and political theory. We will not attempt to review such work here, ${ }^{7}$ and acknowledge that other normative approaches adopted by political philosophers to think through human/animal relationships might reach quite different conclusions than the one we draw from Donaldson and Kymlicka. Nonetheless, there is something that is foregrounded by Donaldson and Kymlicka's argument that is central to many political approaches to animal ethics that is of comparatively little importance to many moral theories: it stresses that some animals are members of a shared human/animal society. This recognition has significant normative clout. For example, it opens the door to thinking of these animals as part of the 'people' whose common good must be considered in democratic decision making. And-to pre-empt our own argument somewhat-it makes these animals eligible for the rights (and responsibilities!) of community members. The style of the argument, then, is one instantly recognisable to scholars in this new literature, even if the precise content may be challenged.

As such, our methodological goal is comparatively modest: we aim to show simply that taking political philosophy into account can offer worthwhile lenses through which to consider apparently 'moral' questions-questions concerned with individual conduct - about the ethics of eating animals. Political philosophy is not useful solely for thinking about institutional questions, such as (for example) the inclusion of animal 'voices' in democratic decision-making procedures.

On the other hand, the practical goals of the present paper are quite ambitious. We aim to show that, in some but not all cases, there is a distinct and potentially action-guiding wrong involved in the consumption of animal products, even if said consumption does not have a causal relationship with any actual harm to animals. (For example, no animals were killed for that act of consumption, and no animals will be killed because of that act of consumption.) And this could show why the strict vegan should be reluctant to embrace freeganism.

\footnotetext{
7 For literature reviews, see Ahlhaus and Niesen (2015); Cochrane et al. (2018), Kymlicka and Donaldson (2016); and Milligan (2015).
} 


\section{False Starts}

We begin with several strategies for defending the wrongness of freeganism that are not particularly promising. For instance, someone could maintain that it's wrong to benefit from wrongdoing, and that principle applies to eating any food produced wrongly, even if it would otherwise go to waste. However, it's simply implausible that it's always wrong to benefit from wrongdoing. First, if that were true, then it would apply equally well to many standard vegan practices. Many vegans go to non-vegan restaurants and order vegan meals. However, those restaurants are made profitable, in part, by the sale of animal products. So, the availability of vegan products at those establishments depends, in part, on the availability of (wrongfully acquired) animal products, which means that vegans are benefiting from wrongdoing when they eat at those restaurants, and are thus (according to this argument) acting wrongfully. On the plausible assumption that this is too demanding a standard, we should reject the moral premise. Second, note that, quite apart from any concerns about the ethics of diet, we are constantly in the position of benefiting from historic wrongs. We benefit from all the horrific things that our ancestors did, and so if it's wrong to benefit from wrongdoing, then we're all living immoral lives. Although that's a bullet we can bite, it seems a rather extreme position to take. Third, it's worth noting that at least some instances of freeganism, such as eating the corpse of an animal killed by a freak accident, don't involve benefiting from any wrongdoing. Thus, even those willing to accept the general principle don't have an argument against all freegan practices.

Another possibility, defended by Julia Driver (2015), is that even if you aren't complicit in wrongdoing, and even if you don't in fact endorse the practice of killing and eating animals, you may still seem to endorse the practice of killing and eating animals when you consume scavenged animal products. This sends a signal to others about what's normal. Driver herself points out that this won't cover every case: there may be circumstances where everyone is aware that you don't endorse the killing of animals and appreciates your reasons for being so opposed. And, of course, you could just eat scavenged animal products in secret. So, this isn't a perfect solution to the problem, but for all that, it may still cover a wide range of cases.

Or, at least, so it seems at first blush. On reflection, though, concerns about causal inefficacy arise. As Julia Nefsky (2018) observes, even if our behaviour can send signals to others, it doesn't follow that those signals are detected, much less that they have any appreciable impact on others' behaviour. Quite often, no one takes any notice of what we do; we operate in the backgrounds of their lives, and we don't have any impact on them whatsoever. In other circumstances, people notice but simply aren't affected; they don't care what we do for one reason or another. In other circumstances still, people notice and care, but simply aren't affected in any significant way. Someone knows that you are an animal advocate and sees you eating meat. She comes to believe that you're a hypocrite, and thereby discounts whatever you say about animals in the future. However, since 
this person was already strongly inclined to discount whatever anyone said about animals, the change doesn't count as a significant one: you had very little chance of changing her mind to begin with, and your having less now isn't at all important. Given the low odds that any individual consumer makes a difference, and the low odds that you might influence any individual in such a way that she alters her purchasing behaviour, it seems highly unlikely that an expected utility calculation will come out in favour of abstaining from consuming scavenged animal products on signalling grounds. ${ }^{8}$ So, influencing others is not going to be the way to defend the wrongness of freegan practices. But Driver offers other strategies for criticizing freeganism.

Driver observes that freeganism 'allows people to bypass norms' (2015, p. 76). This is because a 'system is established whereby some people habitually benefit from the misdeed of others, allowing them to reap the benefits without the dirty hands. But this makes the habitual dumpster diver look like he is bypassing norms as well' (2015, p. 76). However, the concern about bypassing norms falls prey to the same objection that undermines the 'don't benefit from wrongdoing' strategy. If vegans regularly visit non-vegan restaurants, they habitually benefit from the misdeeds of others, allowing them to reap the benefits without the dirty hands. In fact, the point applies just as well to vegan restaurants, which depend on supply chains that would not, at present, be economically viable if they weren't also distributing animal products. Moreover, to echo a point made earlier, the 'bypassing norms' approach would not account for any putative wrongness of freegan practices that don't rely for their existence on wrongful harms to animals.

Driver makes one additional move. She observes that there may be something amiss in the character of freegans: "if the dumpster diver would be disappointed to see everyone become a vegetarian, and thereby also be unable to benefit anymore from the wrongdoing of others, then he does seem to have a character flaw: a failure to exhibit the right attitude toward wrongdoing' $(2015,76)$. This seems unfair. First, Driver doesn't consider the kinds of vices that the strict vegan may display by not consuming freegan foods: e.g., callous disregard for the suffering of animals in plant agriculture, or a self-indulgent obsession with moral purity. So even if freegans are vicious in the ways that Driver suggests, it isn't obvious that strict vegans have better characters. Second, it's unclear that freegans must have the wrong attitude toward wrongdoing. In principle, they might desire the end of animal exploitation while still being convinced that, in the interim, they should minimize waste and avoid contributing to animal exploitation by purchasing consumer goods, many of which are, more or less directly, causally connected to animal exploitation. This seems like a commendable motivation and hardly evidence of a character flaw.

\footnotetext{
${ }^{8}$ For the purposes of this response to Driver, we are assuming an act utilitarian framework. So, the way to assess whether you have an obligation to adjust your behaviour based on what it signals to others is to compare the expected utility of a meat-consuming signal versus that of a plant-consuming signal. This involves calculating the probability of having an impact on the people who are ostensibly picking up the signal, discounted by the probability that their actions make a difference. For an extended discussion of the problem of causal inefficacy in animal ethics, see Budolfson (2019).
} 
So far, the freegan appears to have the upper hand in their debate with the strict vegan. If we want to find reasons to defend the strict vegan from the freegan challenge, we'll need to look elsewhere.

\section{Meat and Respect Conventions: A Partial Case for Strict Veganism}

Animals, with the possible exception of some companions, are not currently perceived as members of our society. So, to go back to our earlier examples of what society membership might mean, animals are not routinely perceived as part of the 'people' whose good must be considered in democratic decision making, and nor are they routinely thought to be entitled to the rights that come with community membership. This non-recognition, it might be thought, is an important cause of our disrespect for them. Perhaps, then, a proposal that we open up society's membership to animals could form the basis of an argument against the freegan on the permissibility of eating meat. After all, if we choose to conceive of animals as cosociety-members, then we are opting to have a relationship with them that precludes seeing their dead bodies as resources at our disposal. ${ }^{9}$ When it comes to the corpses of human society members, we have strong intuitions and strongly integrated social practices about respectful treatment. Often, though not always, ${ }^{10}$ the latter are backed up by the threat of legislative censure. Now, it isn't uncommon to hear talk about the respectful treatment of animal corpses, but this sometimes pans out in a very different way. In particular, one sometimes hears the claim that to use an animal's corpse-especially for food-is to respect the animal, while to use a human's corpse (again, perhaps, especially for food) would be the height of disrespect. To not use an animal's body is 'wasting' it, while we have different intuitions in the human case. As Chloë Taylor observes, 'the dominant Western worldview is deontological with respect to dead humans and utilitarian with respect to dead animals of other species' (2013, p. 95).

But might this difference be accounted for by people's preferences? After all, most of us would prefer for our corpse not to be eaten after we die. Reflection shows that this preference won't vindicate the difference in intuitions. Some humans don't have preferences about their corpses, either because they don't understand the issues, or because they genuinely don't care. Others might have preferences that go strongly against the intuitions. The late music producer Kim Fowley, for example, 'contacted the magazine Girls and Corpses with the request that his corpse feature

\footnotetext{
9 The strict vegan, though presumably not the vegetarian, might add that thinking about society membership in this way would preclude seeing the products of animals' bodies as resources. This thought will be challenged later.

${ }^{10}$ In British law, for example, there are common-law offences concerning causing a public nuisance, outraging public decency, and preventing lawful and 'decent' burial. One anomalous case also saw a defendant plead guilty to 'mutilating a corpse', but this appears to have been a 'legal error' (Jones, 2017, p. 603). Statutory offences exist concerning sexual penetration, and certain forms of professional misconduct. There's no general offence concerning private acts of corpse desecration, however. For a discussion with a proposal for such an offence to be created, see Jones (2017).
} 
on a centrefold. He said that the models "could mutilate the body, providing real blood \& guts and set my bones and blood on fire", (Jones, 2017, p. 618). (We take no stand on whether Girls and Corpses might permissibly use Fowley's body in that way, and acknowledge that the case raises complicated questions about gender and sexuality. Our point is simply that people can and do give consent and express preferences for all kinds of grotesque things.) While certain kinds of corpse-use are generally considered permissible with the consent of the deceased, other kinds (in broader society, if perhaps not the philosophy seminar) aren't. Someone could object that using the corpse of the person who doesn't, or can't, care-or the corpse of an eccentric music producer-is contrary to the preferences of the late human's family or friends. Of course, the individual may not have any family or friends, or their family or friends may not mind if the corpse is used in all kinds of unpleasant ways, or else their preferences might not carry the weight that they're taken to.

If appealing to the preferences of individuals can't do the theoretical work, what alternatives do we have? One possibility is to point to reverence for corpses as an important societal norm. It's part of what it means to belong to our society that your corpse is treated in a particular way. It is - and we do not take this to in any way diminish its significance-a convention about what counts as respectful. ${ }^{11}$ The thought is that part of what it is to be a member of a particular society or shared endeavour is to adopt a certain set of conventions for expressing certain fundamental moral values and goals. Obviously, these are culturally and contextually specific conventions; shaking hands need not mean in one context what it means in another. However, the underlying moral significance is stable across those differences-we are looking for ways to express 'You matter' or 'We are equals', and different communities will find their own ways to accomplish this goal. Accordingly, when we follow these norms, we are expressing something about the value or dignity of others, even if we aren't consciously trying to express such things.

On the other hand, to fail to extend these forms of respect to certain other members of our community seems to deny the mattering, equality, value, or dignity of these others. Or, at least, it does so if we fail to extend these norms without a very good reason. There is something undignified about sharing intimate photographs of a corpse with strangers. But this is an indignity that we tolerate when, for example, photographs from an autopsy need to be shared with a jury.

Crucially, no individual can simply decide on new rules of respect and reverence. Because they serve to coordinate the behaviour of a wide range of individuals, most of whom are strangers, they must be determined at the group level, not by each individual. So, whatever your preferences regarding your own corpse, it remains the case that there are certain constraints on what counts as respectful treatment; it's not entirely up to you to decide what would count as showing due respect for you and your body.

Obviously, there are plenty of other reasons why we shouldn't use the bodies of dead human beings as fuel to produce electricity, or as fertilizer in gardens, or whatever else. As above, people (generally) don't want their bodies to be used in these

\footnotetext{
${ }^{11}$ Compare Buss (1999) and Stohr (2018).
} 
ways. Their relatives (generally) don't want such uses either. We can add that the living might become ill. And so on. But this account helps explain why the norm might be worth following even when these additional kinds of considerations aren't available, and it explains why the arbitrariness of our norms is a feature, rather than a bug. So, let's assume that this is a plausible story about how norms about human corpses might be defended.

The strict vegan can thus present the freegan as acting in a morally dubious way by failing to extend these norms of corpse respect to animals, even this failure does not actually harm any animals. The freegan can't rebut this argument simply by appealing to the benefits of using corpses. Just as there are cases where the norm against using a human corpse may be 'overly restrictive'-we can imagine cases where it really would be useful to put a human corpse to work in a certain way deemed beyond the pale in our society - the norm doesn't admit this kind of flexibility. (Again, there is flexibility when it comes to very good reasons speaking against the norm. As we have defined the term, for example, the strict vegan will still allow the eating of animal products in genuine emergencies. Equally, genuine emergencies will permit treatment of human corpses that would normally be beyond the pale.) To treat animals as members of human communities requires complying with these norms even when the stakes are higher, and the considerations that seem to support the norm aren't salient. This approach seems to fit with a lot of popular vegan rhetoric, much of which takes the form 'If you wouldn't do it to a human, you shouldn't do it to an animal'.

But here's the problem: even if strict vegans-explicitly or otherwise-want to extend this norm of corpse treatment to include animals, why should freegans care? Is there any reason that the freegan is required to adopt the standards of the strict vegan? We think that there is a way for the strict vegan to insist that there is - but it's an answer found in political philosophy, not moral philosophy.

\section{Animal Citizenship: The Case for 'Restricted Freeganism'}

Sue Donaldson and Will Kymlicka (2011) challenge the exclusion of animals from the demos - the 'people' who make up a society. They offer a political account of animal rights in which animals are conceptualised as belonging to one of three categories, with their classification dependent upon the nature of their relationship to a mixed human-animal society. Domesticated animals are offered citizenship, wild animals are offered sovereignty over their own spaces, and 'liminal' animals (who are neither fully wild nor fully domesticated) are offered denizenship. While all sentient animals are afforded key basic (negative) rights, the positive entitlements owed to animals vary depending upon their group membership.

On this picture, as earlier, we ought to give the corpses of domesticated animals the same respect that owed to the corpses of humans. This is because domesticated animals are citizens of the same society as humans. Donaldson and Kymlicka do raise the issue of corpse respect, though only in passing, in the context of 
a discussion about the feeding of carnivorous animals. ${ }^{12}$ They say that some of the ideas people have about the treatment of corpses

are culturally (and religiously) variable, marking the boundaries of community. This could mean that while there are some ways in which we should never treat a corpse - human or animal, citizen or foreigner - there are special obligations we owe to members of the community... Perhaps, then, we ought to treat the bodies of domesticated animals the same way as human bodies in any given society or community, but the same obligation does not apply for corpses of those from outside the community. (2011, p. 151)

So, we get a critique of certain freegan practices (namely, those involving the bodies of domesticated animals) though not of others (namely, those involving the bodies of wild animals and almost-wild 'liminal' animals). This seems to solve the most pressing problems facing the last view. First, Donaldson and Kymlicka aren't simply presenting a relationship that we might choose to have with animals, as was our strict vegan; instead, the relationship is framed as mandatory. Their reasons for this will be discussed shortly. Second, we may be able to block strange implications that could arise from the previous view. For instance, if corpses along the side of the road belong to liminal or wild animals, we don't necessarily owe them special honour or care. So, for example, burial rites won't be morally required. They may still be required for domesticated animals, but this isn't a particularly difficult bullet to bite, and is precisely the kind of thing that Donaldson and Kymlicka would welcome.

Obviously, this won't be satisfying to someone who wants a perfectly strict veganism. We can borrow from Donaldson and Kymlicka to place limits on freeganism, but not to condemn it altogether. After all, it doesn't follow from the above that there is anything wrong with dumpster-diving for products made from dairy or eggs. Milk and eggs aren't corpses, and, to be clear, Donaldson and Kymlicka's explicitly do not oppose the consumption of these products-only harmful practices associated with it (2011, pp. 134-9). This is consistent with the desire to see corelationships with animal citizens governed by the same kinds of rules that govern co-relationships with human citizens. It isn't (and shouldn't be) seen as disrespectful for humans, such as young infants, to drink human breastmilk, such as the milk of their mothers. In human culture, breastmilk is food (or consumable) in a way that human flesh (almost) invariably isn't. ${ }^{13}$ And, while humans don't lay eggs, human placentas are sometimes consumed after the birth of infants. While some might find this distasteful, the thought certainly doesn't evoke the same horror as the consumption of corpses-and rightly so.

What's more, and as we've noted, Donaldson and Kymlicka's approach doesn't obviously provide resources for rejecting the consumption even of all animal flesh.

\footnotetext{
12 This is an interesting and important concern, though orthogonal to the present enquiry. For more, see Milburn (2015) and Milburn (2017).

13 For more on milk as food, and how this grounds the in-principle permissibility of consuming the milk of animals on an animal-rights account, see Milburn (2018).
} 
From what we've said so far, roadkill-assuming the dead animal wasn't domesticated-would remain on the table, as it were.

Someone might hope otherwise. The strict vegan might say that if animals killed on the road fall into the category of 'liminal' animals, then there are difficult questions to be answered about the kind of community to which they belong, and so about the kinds of norms that should govern respectful treatment of them. In short, do we treat them respectfully when we treat them as members of our own community, or when we treat them as if they are members of sovereign animal communities? The strict vegan might insist that some moral caution is appropriate, according to which we ought to offer liminal animals certain kinds of respect simply to mitigate the risk of misinterpreting our obligations to them. While eating or not eating the corpses would be consistent with respect in a sovereign animal community (insofar as such communities don't have norms of respectful corpse treatmentmore on this in a second), eating it would be the epitome of disrespect in a Western human community. Thus, not eating the corpse seems like the 'safe' option.

However, intuitions are going to pull in different directions, here. Consider a feral pig who lives on the outskirts of human society who's blamelessly hit by a car, in contrast to a wholly wild boar killed by a rival deep in the backcountry. If the strict vegan's extension of Donaldson and Kymlicka's argument works, then it should be more objectionable to collect, butcher, cook, and consume the body of the former animal than the latter. But we can imagine environmental ethicists being highly concerned about disturbing a pristine forest while being utterly unconcerned about eating the body of a member of an invasive species, and it isn't clear that their reaction is mistaken. So, while the ambiguity of the pig's relationship with us may generate some special reasons to act-humans may be more responsible for the plight of feral pigs than they are for the plight of the wild boar ${ }^{14}$ — these reasons may not be obligation-generating, as they may be outweighed by other considerations.

Finally, it's implausible that there's going to be a way to seriously curtail the consumption of bodies of (unambiguously) wild animals on this account, unless they themselves have social practices to which we ought to defer. However, it's hardly obvious that this is so, even among social and highly intelligent animals: while members of some species engage in 'mourning' behaviour, it isn't obvious how to understand it, especially its significance for corpse consumption. Of course, it's possible that certain animals have modes of respectful treatment of the dead that are inconsistent with corpse-consumption, so we allow that there may be certain wildanimal bodies that are 'off-limits' on this account. However, those would be the exception rather than the rule: there is no reason to think that crocodiles or crickets have such social practices.

$\overline{{ }^{14} \text { For more on this, see Palmer }}$ (2010). 


\section{A Last-ditch Defence of Strict Veg(etari)anism?}

The strict vegan might think that these considerations about community are all beside the point. Why can't Donaldson and Kymlicka simply reject the consumption of all corpses, whatever their origin? On this view, meat-eating would run up against one of the 'ways in which we should never treat a corpse' (Donaldson \& Kymlicka, 2011, p. 151), regardless of societal membership.

This line is indeed available, but we think it ought to be resisted. Presumably, it's motivated by the idea that there's something objectively wrong with corpse consumption: not eating corpses isn't just good 'manners'; it's demanded by a universal duty. This is implausible. The consumption of corpses as a part of a funerary rite is uncommon in the twenty-first century, though it was certainly practiced by some human communities into the twentieth century. ${ }^{15}$ There's no good reason to think that there's anything inherently wrong with what those people did. What's more, there's no good reason to think that attitudes towards the consumption of human flesh couldn't change, meaning that the consumption of the flesh of nonhuman citizens would become less problematic. ${ }^{16}$ Indeed, perhaps cannibalism isn't as alien to Western practices as we might assume. The Roman Catholic doctrine of transubstantiation holds that believers eat the literal body and blood of Christ when receiving the Eucharist. If there is nothing wrong with that practice, which is certainly one that occurs in Western culture, then we have no basis for denying that our eating (parts of some) dead humans is perfectly consistent with respecting said humans. Perhaps a change in our attitudes to animals will itself prompt a change in norms about how corpses are treated. The animal ethicist Bernice Bovenkerk, for example, has said that she would prefer for her body to be fed to wild animals after her death (van Dinther, 2020). (This is something practiced in certain non-western contexts.) We have no great quarrel with Bovenkerk's position, and do not envisage that Donaldson and Kymlicka would, either. The point (indeed, Bovenkerk's own point) is that the corpses of animals and humans should not be treated in some grossly different way purely because of species membership. Whether we should persist with our current norms of corpse treatment or seek to change them is a separate questionthough one surely worth asking.

Second, there is something presumptuous about taking our norms of respect and treating them as sacrosanct for interactions with those outside our culture, even if we regard them as sacrosanct for those within. If you come from a culture that buries its dead, and you find the body of a person from a culture that cremates its dead, then it seems very plausible that it's permissible for you to cremate the body, even if your culture normally condemns such behaviour. Mutatis mutandis, the same applies to bodies of those from communities (including wild animal sovereign communities)

\footnotetext{
15 Including the Wari', of the Western Amazon.

16 Indeed, one of us (Milburn 2016) has previously argued for a society in which in vitro human flesh is consumed alongside in vitro nonhuman flesh. In vitro nonhuman flesh is desirable because it can minimise harm to animals by those reluctant to give up meat, while in vitro human flesh breaks down false human/animal' dichotomies and hierarchies.
} 
where corpse consumption is a considered a respectful or unobjectionable practice. So again, there's no reason to think that this is something 'we' ought always to avoid. As a result, Donaldson and Kymlicka aren't going to be able to rule out the consumption of all animal flesh.

There is one more strategy that the strict vegan might try to employ here. To see this possibility, it will help to disentangle two lines of reasoning that Kymlicka and Donaldson offer for their view. On the one hand, they think that the political status of animals is one that simply needs to be recognized; it doesn't need to be created based on a mixture of practical and moral considerations. Animal ethicists, they argue, have tended to view animals as part of an 'expanding circles' model of society, according to which a history of moral inclusion begins with the self, and then expands to the family, the neighbourhood, the nation, humanity, and-eventually_to an 'interspecies cosmos' (Kymlicka \& Donaldson, 2016, pp. 693-4). This, they say, is mistaken:

Animals are alongside us at every stage of these expanding circles. The vast majority of people in North America with companion animals insist that their companion dogs and cats are 'members of the family': we are born into interspecies families and learn our concept of 'family' in this context. (2016, p. 694, emphasis in original)

We might say the same of our wider community. The process of domestication itself is one of humans and animals coming to live together, which Donaldson and Kymlicka compare to the North-Atlantic slave trade. Slavery was unjust, but the solution to that injustice cannot be the extinction of African Americans or their repatriation to Africa: people held as slaves were, effectively, made into marginalized citizens through their enslavement, and are now owed recognition as full citizens (Donaldson \& Kymlicka, 2011, p. 79). Likewise, Donaldson and Kymlicka argue, domesticated animals should be recognized as full citizens.

On the other hand, there is a more interest-oriented line of reasoning. Donaldson and Kymlicka claim that it is in the interests of some animals (particularly domesticated animals) to continue to have a close relationship with humans, though in a heavily modified form. This is complicated, because the close relationships that human communities have had with certain animals have usually been extremely harmful. They've involved the confinement of animals, infliction of violence upon them, the exploitation of their labour and bodies, and so forth. Given this history, it's an open question as to the kinds of connections we should have with animals going forward. ${ }^{17}$

Now, in a standard situation of historical abuse, we might think that it would be the decision of the victim whether a relationship continues once the abuse

\footnotetext{
17 Donaldson and Kymlicka face challenges from the 'extinctionist' animal-rights theorists who support eradicating domesticated animals entirely; they also face challenges from interest-based animal rights theorists who support continued relationships between humans and animals but deny that citizenship rights are in animals' interests. No doubt, too, someone could be broadly sympathetic to Donaldson and Kymlicka's approach, but dispute precisely what a citizenship relationship entails, dispute the line between citizen and denizen, question whether a particular animal benefits from citizenship, and so forth.
} 
has been eradicated. And a recognition of animal agency is crucial for Donaldson and Kymlicka: 'given a range of non-coercive alternatives, animals can express preferences (i.e., "vote with their feet") about how to live their lives, and under what circumstances, if any, to engage with humans' (2011, p. 66). But this can only take us so far; at some level, humans must make a choice on animals' behalf. This is going to include choices on the macro scale between continued co-relationships or extinction, and on the micro scale as to which 'group'domestic, wild, liminal—a given animal belongs.

Donaldson and Kymlicka see these two lines of reasoning-historical and interest-based-as two sides of the same coin. Together, they form the basis of their claim about the compulsory nature of our having a certain kind of relationship with domesticated animals. Crucially, for current purposes, this relationship is one that demands that domesticated animals' bodies be treated with the kind of respect that would be afforded to the bodies of other co-citizens.

How could the strict vegan use these observations to ground a 'zoopolitical' case against (restricted) freeganism? First, they might observe that we live in the Anthropocene, an age defined by ubiquitous human influence on the natural world. When we recognize the complex historical relationship that we have with animals, our influence clearly doesn't end at domesticated beings, or even at the liminal ones. We have done so much to reshape the environment in which animals live that if our influence-particularly our negative influence-is enough to generate a citizenship claim for those animals with whom we are entangled, then (nearly) all wild animals have some such claim. Second, when we consider the degree to which animals have an interest in being treated as citizens, it may not be obvious why denizenship and sovereignty would actually be preferable to citizenship. After all, that could only mean less aid in circumstances where it would be advantageous to have it, and less representation in circumstances where they would benefit from having an advocate in the decision being made. Plainly, there is much more to say here, and we don't want to suggest that Donaldson and Kymlicka have no resources for replying to these objections. Instead, we simply want to note that the strict vegan has the resources to criticize even a restricted freeganism if she can make these objections stick.

After all, if it's indeed the case that all animals have a claim to citizenship, then all animal bodies are protected by the 'respect for corpses' norm. So rather than our limited critique of freeganism, we get closer to the wide-ranging one that our hypothetical strict vegan wanted. In all likelihood, this means that Donaldson and Kymlicka's zoopolis has turned into some kind of cosmozoopolis. This is a term we borrow from Cochrane (2013; cf. Cochrane, 2018), with the caveat that it isn't clear that his cosmozoopolitics carries these consequences. Opening up society this far, however, may come with costs, such as highly implausible implications about our duties concerning the corpses of wild animals. Must all be respectfully buried? Strict veganism may be appealing, but it isn't worth any cost whatsoever. If we would have to take on such counterintuitive consequences to salvage it, then it may not be worth salvaging. 


\section{Concluding Remarks: The Enduring Appeal of Unrestricted Freeganism}

If we buy into the claims of Donaldson and Kymlicka about animals and community membership, then we have a principled argument against (certain forms of) freeganism. There are some responses that freegans could make. They could say that the wrong of disrespecting the animal's corpse pales in comparison to the wrongs that the animal has faced at the hands of the humans who inflicted suffering upon, and killed, her. It might also pale in comparison to the disrespect that the corpse has already faced-butchery, packaging, sale, and perhaps labelling with pictures or claims relating to the happiness of farmed animals. All of this is plausible, but none of it serves to mediate the putative wrong in continuing to disrespect the corpse by eating it. We wouldn't find similar claims plausible in the human case. At the same time, though, it strongly suggests that vegans should not be tempted to view freegans as the enemy: even if there is some disagreement, it pales in comparison to the disagreement that both have with conventional meat-eaters. Even if there are moral considerations that tell against what freegans are doing, they are much weaker than the reasons that tell against producing and distributing non-vegan foods.

A better reply open to the freegan is to say that even if eating a corpse involves disrespect, the prima facie wrong of this disrespect can be outweighed by the fact that the alternative option is paying for products made from crops harvested in ways that kill animals_-precisely the argument with which we began the paper. Put bluntly, better to (in a sense) disrespect an animal already dead than contribute to the killing of more animals. If we follow Donaldson and Kymlicka, however, then we won't regard this as a knock-down argument. The doctrine of double effect might prove useful, here: we could argue that it's worse to disrespect an animal corpse as a means to a good end (namely, securing free food) than it is to harvest plants, even though it's a foreseen but undesired side-effect of such harvesting that it results in the deaths of some animals (on this, see Lamey, 2019). One could also observe that, on relational accounts of animal ethics, like that offered by Donaldson and Kymlicka, we may have stronger duties concerning domesticated animals (such as farmed animals) than wild/liminal animals (such as those killed in the harvesting process). ${ }^{18}$ Granted, there are a range of ways to weigh these considerations, but it's far from clear that the freegan has the upper hand they seemed to have at the start of this exploration.

On that note, let's return to Bruckner. Have we shown that his argument fails? Not exactly. Instead, what we've argued is that if we are willing to build on Donaldson and Kymlicka's zoopolitics, then Bruckner is too quick, just as it's too quick to generalize from his argument to cover all freegan practices. Domesticated animals, on Donaldson and Kymlicka's picture, deserve a form of respect similar to the one we show human members of our society, and so we have reason not to collect and eat their bodies - though, of course, nothing follows from this about it being wrong

18 Again, see also Palmer (2010). 
to eat the bodies of wild animals, especially when doing so can alleviate harm elsewhere. But, when push comes to shove, there aren't that many freegans picking up roadkill. The more interesting cases are the more familiar ones: dumpster-diving for a can of beef stew or eating a ham sandwich that would go to waste after a faculty meeting. The restricted freegan is committed to saying that this would be to disrespect the corpses of cows and pigs. On the other hand, restricted freeganism can permit dumpster-diving for a block of cheese, or finishing off the egg-salad sandwiches going to waste after the departmental meeting, as these cases don't involve meat, and thus do not entail (according to the argument here presented, at least) disrespect for a corpse. But rather than a bug of the theory, we regard this as a feature. The approach offers a justification of the intuition, shared by many vegans (and, obviously, by many vegetarians), that there's something particularly problematic about eating the flesh of animals. ${ }^{19}$ And if neither the strict vegan nor the freegan gets exactly what she wants from the approach, there may still be a great deal to be said for it - just as there may be a great deal to be said for the more general value of political philosophy for the ethics of eating animals. ${ }^{20}$

Open Access This article is licensed under a Creative Commons Attribution 4.0 International License, which permits use, sharing, adaptation, distribution and reproduction in any medium or format, as long as you give appropriate credit to the original author(s) and the source, provide a link to the Creative Commons licence, and indicate if changes were made. The images or other third party material in this article are included in the article's Creative Commons licence, unless indicated otherwise in a credit line to the material. If material is not included in the article's Creative Commons licence and your intended use is not permitted by statutory regulation or exceeds the permitted use, you will need to obtain permission directly from the copyright holder. To view a copy of this licence, visit http://creativecommons.org/licen ses/by/4.0/.

\section{References}

Abbate, C. E. (2019a). Save the meat for cats: Why it's wrong to eat roadkill. Journal of Agricultural and Environmental Ethics, 32(1), 165-182.

Abbate, C. E. (2019b). Veganism, (almost) harm-free animal fleesh, and Nonmaleficence. In B. Fischer (Ed.), The Routledge handbook of animal ethics (pp. 555-568). Routledge.

Ahlhaus, S., \& Niesen, P. (2015). What is Animal Politics? Outline of a new research agenda. Historical Social Research, 40(4), 7-31.

Archer, M. (2011). Slaughter of the singing sentients: Measuring the morality of eating red meat. Australian Zoologist, 35(4), 979-982.

\footnotetext{
19 Note that this is not a point about killing or selling, but eating. The approach we're exploring here avoids familiar problems about closing the gap between the ethics of production and purchasing, on the one hand, and the ethics of consuming, on the other. It also avoids contentious arguments attempting to ground the particular wrongness of meat-eating in claims about the comparative harm of meat production and egg or milk production. Indeed, the arguments explored here could be expanded into an argument specifically for vegetarianism, rather than veganism. See Milburn (2020).

20 The authors thank reviewers and editors at the Journal of Agricultural and Environmental Ethics for some helpful suggestions. A previous version of this paper was presented to the University of York's Practical Philosophy Group, and thanks are offered to the audience. Josh Milburn's research at the University of Sheffield is funded by the British Academy (grant number PF19\100101), and he offers thanks to the British Academy, the University of Sheffield, and his mentor (Alasdair Cochrane).
} 
Bruckner, D. W. (2015). Strict vegetarianism is immoral. In B. Bramble \& B. Fischer (Eds.), The moral complexities of eating meat (pp. 30-47). Oxford University Press.

Budolfson, M. (2019). The inefficacy objection to consequentialism and the problem with the expected consequences response. Philosophical Studies, 176(7), 1711-1724.

Buss, S. (1999). Appearing respectful: The moral significance of manners. Ethics, 109(4), 795-826.

Chignell, A. (2016). Can we really vote with our forks? Opportunism and the threshold chicken. In A. Chignell, T. Cuneo, \& M. C. Halteman (Eds.), Philosophy comes to dinner (pp. 183-202). Routledge.

Cochrane, A. (2012). Animal rights without liberation. Columbia University Press.

Cochrane, A. (2013). Cosmozoopolis: The case against group-differentiated animal rights. Law, Ethics and Philosophy, 1, 127-141.

Cochrane, A. (2018). Sentientist politics. Oxford University Press.

Cochrane, A., Garner, R., \& O'Sullivan, S. (2018). Animal ethics and the political. Critical Review of International Social and Political Philosophy, 21(2), 261-277.

Cooks, L. (2017). The end(s) of freeganism and the cultural productions of food waste. In M. Wallace \& D. Carruthers (Eds.), Perma/culture: imagining alternatives in an age of crisis (pp. 195-206). Routledge.

Corman, L. (2011). Getting their hands dirty: Raccoons, freegans, and urban 'trash.' Journal for Critical Animal Studies IX, 3, 28-61.

Curnutt, J. (1997). A new argument for vegetarianism. Journal of Social Philosophy, 28(3), 153-172.

Davis, S. (2003). The least harm principle may require that humans consume a diet containing large herbivores, not a vegan diet. Journal of Agricultural and Environmental Ethics, 16(4), 387-394.

DeGrazia, D. (2009). Moral vegetarianism from a very broad basis. Journal of Moral Philosophy, 6(2), 143-165.

Diamond, C. (1978). Eating meat and eating people. Philosophy, 53(206), 465-479.

Donaldson, S., \& Kymlicka, W. (2011). Zoopolis. Oxford University Press.

Driver, J. (2015). Individual consumption and moral complicity. In B. Fischer \& B. Bradley (Eds.), The moral complexities of eating meat (pp. 67-79). Oxford University Press.

Fischer, B. (2018). Arguments for consuming animal products. In A. Barnhill, M. Budolfson, \& T. Doggert (Eds.), The Oxford Handbook of Food Ethics (pp. 241-266). Oxford University Press.

Fischer, B. (2020). The ethics of eating animals: Usually bad, sometimes wrong, often permissible. New York: Routledge.

Fischer, B., \& Lamey, A. (2018). Field deaths in plant agriculture. Journal of Agricultural and Environmental Ethics, 31(4), 409-428.

Giroux, V. (2016). Véganisme. In: l'Encyclopédie philosophique. http://encyclo-philo.fr/veganisme-gp/

Jones, I. (2017). A grave offence: Corpse desecration and the criminal law. Legal Studies, 37(4), 599-620.

Kymlicka, W., \& Donaldson, S. (2016). Locating animals in political philosophy. Philosophy Compass, 11(11), 692-701.

Lamey, A. (2019). Duty and the Beast. Cambridge University Press.

Milburn, J. (2015). Not only humans eat meat: Companions, sentience and vegan politics. Journal of Social Philosophy, 46(4), 449-462.

Milburn, J. (2016). Chewing over in vitro meat: Animal ethics, cannibalism and social progress. Res Publica, 22(3), 249-265.

Milburn, J. (2017). The animal lovers' paradox? On the ethics of 'pet food.' In C. Overall (Ed.), Pets and people (pp. 187-202). Oxford University Press.

Milburn, J. (2018). Death-free dairy? The ethics of clean milk. Journal of Agricultural and Environmental Ethics, 31(2), 261-279.

Milburn, J. (2020). A novel argument for vegetarianism? Zoopolitics and respect for animal corpses.A nimal. Studies Journal, 9(2), 240-259.

Milligan, T. (2015). The political turn in animal rights. Politics and Animals, 1, 6-15.

Nefsky, J. (2018). Consumer choice and collective impact. In A. Barnhill, M. Budolfson, \& T. Doggert (Eds.), The Oxford Handbook of Food Ethics (pp. 267-286). Oxford University Press.

Oakes, W. (2000). Why Freegan? (zine). Accessed at https://freegan.info/freegan-philosophy/why-freeganan-attack-on-consumption-in-defense-of-donuts/ in March 2021.

Palmer, C. (2010). Animal ethics in context. Columbia University Press.

Rachels, S. (2011). Vegetarianism. In R. G. Frey \& T. L. Beauchamp (Eds.), The Oxford Handbook of Animal Ethics (pp. 877-905). Oxford University Press.

Singer, P. (1980). Utilitarianism and vegetarianism. Philosophy \& Public Affairs, 9(4), 325-337.

Singer, P., \& Mason, J. (2012). Freeganism and food waste. In A. Barnhill, M. Budolfson, \& T. Doggert (Eds.), Food, ethics, and society (pp. 219-224). Oxford University Press. 
Stohr, K. (2018). The etiquette of eating. In A. Barnhill, M. Budolfson, \& T. Doggert (Eds.), The Oxford Handbook of Food Ethics (pp. 700-721). Oxford University Press.

Taylor, C. (2013). Respect for the (animal) dead. In F. Probyn-Rapsey \& J. Johnston (Eds.), Animal Death (pp. 87-103). University of Sydney Press.

van Dinther, M. 2020. Wageningse wetenschapper: 'Als wij dieren eten, dan mogen dieren ook mensen eten'. De Volkskrant. https://www.volkskrant.n1/wetenschap/wageningse-wetenschapper-als-wij-dieren-etendan-mogen-dieren-ook-mensen-eten b9a5c758/ Accessed March 2021.

Warfield, T. A. (2016). Eating dead animals: Meat eating, meat purchasing, and proving too much. In A. Chignell, T. Cuneo, \& M. C. Halteman (Eds.), Philosophy comes to dinner (pp. 151-162). Routledge.

Publisher's Note Springer Nature remains neutral with regard to jurisdictional claims in published maps and institutional affiliations. 